\title{
LANDSLIDE HAZARD AFFECTING HISTORICAL BUILDINGS: SANTA SCOLASTICA MONASTERY IN SUBIACO
}

\section{MARIALUIGIA SANGIRARDI ${ }^{{ }^{*}}$, ANGELO AMOROSI ${ }^{2}$ AND GIANMARCO de FELICE ${ }^{1}$}

\author{
${ }^{1}$ Department of Engineering, Roma Tre University \\ Via Vito Volterra 62, 00146, Rome, Italy. \\ e-mail: \{marialuigia.sangirardi, gianmarco.defelice\}@uniroma3.it https://www.romatrestrutture.eu/ \\ ${ }^{2}$ Department of Structural and Geotechnical Engineering, Sapienza University of Rome \\ Via Eudossiana 18, 00184, Rome, Italy. \\ Email: angelo.amorosi@uniroma1.it, https://web.uniroma1.it/disg/
}

Keywords: Masonry, Finite Elements, Landslides, Jointed Masonry Model

\begin{abstract}
Every year landslides occur as a consequence of ground conditions, geomorphological, physical or man-made processes, often triggered by heavy rainfalls or earthquakes. They affect buildings and infrastructures, causing economic and life losses. On the Italian territory, more than 14,000 heritage sites interact with potentially unstable slopes.

This work investigates the effects of a landslide, occurred on the 26th of November 2018, on the Monastry of Santa Scolastica in Subiaco (Rome), one of the most ancient and well-preserved examples of medieval architecture in Central Italy. The geometry of the slope was reconstructed based on aerial photographic survey and point-cloud processing, obtaining meshed surfaces and extracting relevant sections.

The mechanical parameters and the specific hydraulic conditions triggering the failure mechanism were first recognised by traditional limit equilibrium back-analyses and then implemented in a 3D non-linear finite element (FE) model, which included both the slope and the interacting portion of the ancient structure. Elastic-perfectly plastic constitutive assumptions were adopted for the soil, while the structure was modelled by a three-dimensional anisotropic elastic-perfectly plastic constitutive model, specifically conceived for masonry, accounting for block dimensions and staggering joints effects.

Finite element approach proves to be very effective in the analysis of such a coupled interaction problem, leading to a realistic representation of the interplay between the soil displacements and their deformative effects within the structure. The numerical results have been interpreted to highlight the structural response in terms of crack pattern and stress distribution as induced by the interaction with the deforming slope, leading to a quantitative evaluation of the landslide-induced damage. Several scenarios were simulated: first, the prelandslide existing crack pattern was reproduced, then the event was modelled as it occurred, evaluating its consequences on the structure.
\end{abstract}




\section{INTRODUCTION}

The evaluation of the impact of natural hazards on world's architectural heritage is a complex, though intriguing, task for the scientific community, which necessarily requires interdisciplinary approaches to be analysed and solved.

Together with earthquakes, landslides are one of the most destructive geotechnical hazards affecting constructions, economy and, more in general, the quality of life of the communities populating the hit areas. In fact, though most of the landslides usually occur in rural districts, they can cause significant damage to infrastructures [1] and have not rarely caused severe damage to monuments.

Slope movements are essentially related to the instability conditions occurring once the overall mobilised shear stresses along a slip surface equal the available shear strength. Such conditions can be triggered by various phenomena, including modifications of the morphology of the slope, groundwater effects leading to increased pore-water pressures or static and/or dynamic actions affecting the soil mass. In some cases risk is increased by some predisposing factors, such as land urbanization of the hill-sides.

Some well-known examples of UNESCO Sites subjected to landslides hazard or effects are, among others, the right coast of the river Moskow (Russia), Machu Picchu (Peru) cultural heritage site or some villages in Italy like Orvieto and Rocca Ripesena [2].

Italy, with reference to landslide hazard, is recognized as a very vulnerable country: 620,808 landslides have been identified on the national territory, constituting around the $80 \%$ of the total number of landsides in Europ. In particular, Lazio and Umbria regions are the most affected
[3].
A number of studies deal with the definition or fragility curves at the urban scale, with
particular reference to slow moving landslides [4,5], while analyses at the scale of the building
have also been performed for both reinforced doncrete [6] or nnasoniry structures [7].
The Monastery of Santa Scolastica in Subiaco is a very well-preserved example of medieval architecture and is the most.ancient Benedict's monastery in the world. It is located in a

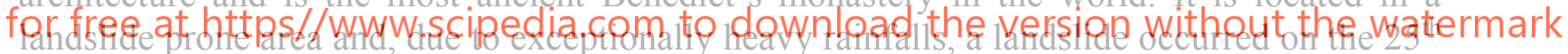

of November 2018 in the vicinity of the structure, causing fear and temporary closing of the

buildings where a monastic community is still settled. The event can be classified as a flowtype landslide, a fast phenomenon, typically triggered by altered hydraulic conditions, as in the case under study, or earthquakes impulsive actions. Damage patterns had already been detected in some portions of the structure well before the landslide: as such, it was essential to assess whether or not the event had further compromised the safety conditions of the monastery.

As a first step, it was necessary to acquire an updated and well-defined sketch of both the slopes and the structure geometries: this was achieved by modern geometrical laser-scanner survey techniques. A classical decoupled approach was then adopted to back-analyse the landslide, by means of two dimensional (2D) limit equilibrium methods. The results of these calculations were then used to define the three dimensional (3D) finite element (FE) model, which not only included the geotechnical details of the soil deposits surrounding and below the monastery but also a fairly realistic representation of the structure. This mixed geotechnical and structural model was used to investigate the whole interaction processes that occurred between the monastery and the soil, including those related to the construction stages of the structure and the ones induced by the landslide. 
In particular, the aims of the study are the following: first to identify and reproduce the detected damage of the structure as induced during and after the construction stages, then to analyse the effects of the subsequent landslide, thus assessing its role on the current safety conditions of the building.

\section{PROBLEM STATEMENT}

The use of numerical methods (finite-element or finite-difference methods) in structural and geotechnical applications is nowadays common, though their effectiveness strongly depends on geometrical discretisation, initial conditions, correct representation of the construction stages, constitutive hypotheses and numerical techniques (e.g.: [8]).

The adoption of elasto-plastic constitutive hypotheses within FE models can be considered as a well-established approach to analyse slope stability problems, though the use of more traditional methods, as those based on limit equilibrium, is still often preferred. This should be ascribed to the aim of the analysis, which typically focuses mainly on failure conditions, thus justifying the use of rather simple limit equilibrium reference conditions and related rigid plastic constitutive assumptions. When used at this scope, the complexity of non-linear FE analyses does not often lead to a gain in terms of accuracy of the solution. On the other hand, when the focus is on the deformation behaviour, either in the pre-landslide stage or in relation to this event, possibly including the interaction with an adjacent structure, FE models provide a far more realistic representation of the phenomena. In fact, they not only satisfy local and global equilibrium conditions up to failure, but also compatibility and constifutive assumptions,

such reproducing the constitutive assumptions

2.1 Landslide modelling

As mentioned above, the modelled landslide has first been back-analysed

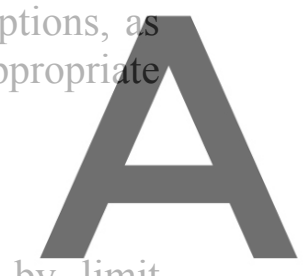

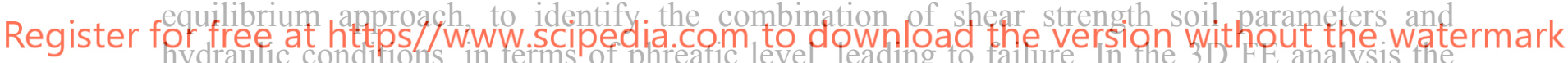
geometry and failure plane of the slope has been reconstructed in light of the survey data and the results of the 2D back-analysis. This latter has also allowed the evaluation of the mobilised strength parameters. The landslide was triggered in the 3D numerical model by imposing a variation of the water table height, as possibly occurred at the time of the event due to heavy rainfalls. In detail, the stages of the analysis are the following: model stress initialization, structure construction and related interaction with the foundation soil, strength parameters degradation of a thin soil layer located at the pre-defined failure slip surface, positive variation of the water table level along the slopes to finally trigger the sliding. In the analyses here discussed, the non-convergence of the solution was considered as a suitable indicator of failure, as discussed in $[9,10]$. When the algorithm cannot converge within a specified maximum number of iterations, no stress distribution can be found that is simultaneously able to satisfy both the Mohr-Coulomb failure criterion and global equilibrium. Under these conditions, failure is assumed to have occurred and it is accompanied by a dramatic increase in the nodal displacements within the mesh. 


\subsection{Constitutive models for soil and masonry}

The constitutive models adopted for the soil and the structure are both formulated according to classic rate-independent plasticity. The soil behaviour is modelled by a linear elasticperfectly plastic constitutive model, characterised by a no-traction Mohr-Coulomb yield criterion and a null dilatancy angle. This is a relatively simple assumption, nonetheless it allows to realistically estimate the main phenomena involving the soil in the slope movement, while also reproducing with reasonable accuracy the interactions between the soil and the structure throughout the whole construction sequence and landsliding processes simulated numerically. In the analyses the bedrock stratum is assumed as rigid, thus not exhibiting any deformation or collapse.

The constitutive model adopted for masonry is a three-dimensional anisotropic elasticperfectly plastic one [11], in which block aspect ratio and staggering joints effects are considered. Macroscopic elastic properties are derived in the framework of homogenisation theory of periodic media, while yielding is characterized by the intrinsic material anisotropy. A set of (maximum) three sliding directions, on which failure is meant to occur, is defined in the $x y z$ space and described by means of dip and strike angles, representing, for each plane, the positive rotation along the $x$-axis and the negative rotation along the $z$-axis, respectively [12]. In the analyses only two planes (head and bed joints) are activated. Yield functions are defined, for each orientation, in terms of local stress components according to Coulomb's and tensile criterion as follows:
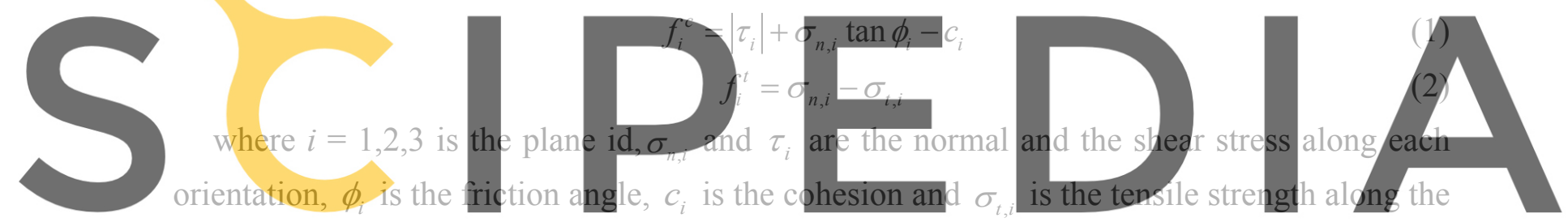

orientation, $\phi_{i}$ is the friction angle, $c_{i}$ is the cohesion and $\sigma_{t, i}$ is the tensile strength aldng the
joints. The interlocking effect is accounted by modifying the strength parameters on the head-

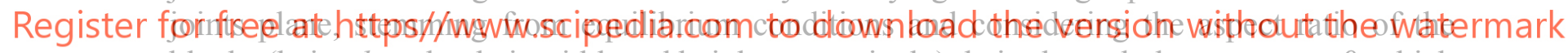
blocks (being $b$ and $a$ their width and height respectively) their through the parameter $\beta$, which depends on the friction angle of the bed joints:

$$
\beta=\tan \phi_{2} \frac{b}{2 a}
$$

Tensile strength and cohesion on the head joints are hence calculated according to the following expressions:

$$
\begin{gathered}
\sigma_{t, 1}=\sigma_{t 0,1}-\beta \sigma_{n, 2}+c_{0,2} \frac{\beta}{\tan \phi_{2}} \\
c_{1}=c_{0,1}-\left(\beta \sigma_{n, 2}-c_{0,2} \frac{\beta}{\tan \phi_{2}}\right) \tan \phi_{1}
\end{gathered}
$$

\section{CASE STUDY}

The Monastery of Santa Scolastica is the most ancient Benedict's monastery in the world. It is located in the Aniene river valley (Lazio, Italy), recognized as the cradle of the Benedict's community. It is an aggregate, developing around three cloisters, a church, a hostel for pilgrims 
and a library. Even if the first settlement dates back to the VI-VII Centuries, the structure has undergone deep modifications during time, and the original configuration was outlined only during the Sixties, thanks to the findings of an archaeological campaign.

In the following, the adopted strategy to reconstruct the geometry of the slope and the structure, the back analysis performed on the slope and the mechanical characterization of the structure are briefly outlined.

\subsection{Geometrical reconstruction of the slope and the structure}

Terrestrial laser scanner or closed range photogrammetry are modern and efficient tools to reconstruct complex geometries; in some recent applications [13], they have also been adopted to directly obtain three-dimensional finite element meshes through a semi-automatic processing of the points-cloud.

In this study, a complete photogrammetric survey of the Monastery and the close surroundings was performed. The points-cloud has been post-processed to determine the detailed geometrical configuration of the structure, the slopes and of the area affected by the earth sliding, all then introduced into the numerical 3D model used to study the interaction between the landslide and the structure.
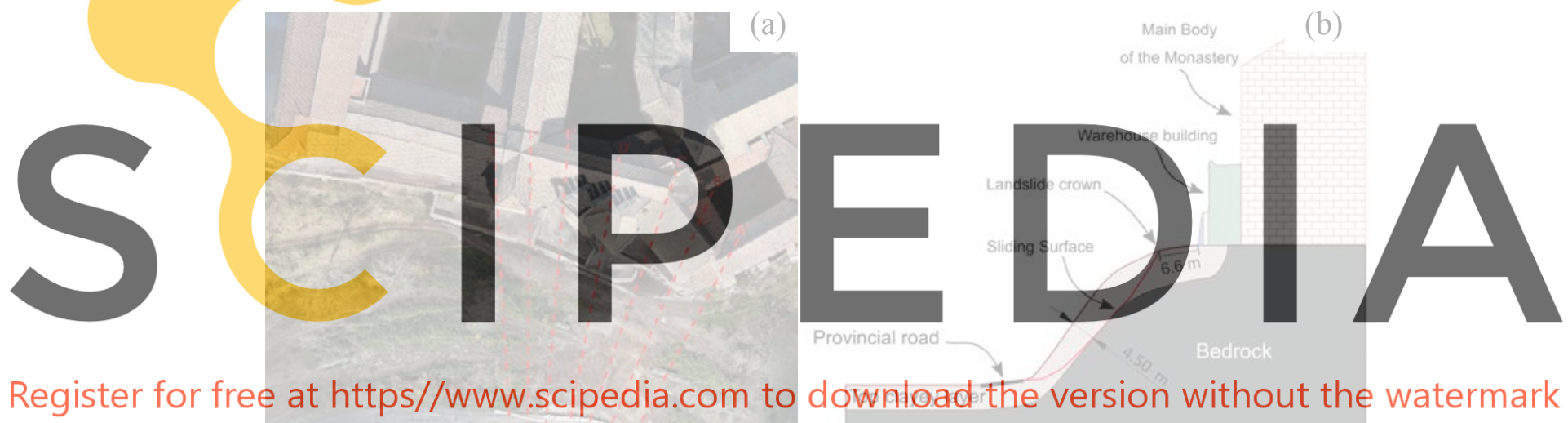

Register for free at https//www.scipedia.com to download the version without the watermark

Figure 1: Aerial view of the selected sections of the points cloud (a) and result of the 2D post-processing of the pre-event geometry (b)

The aerial view reported in Figure 1a shows the position of the selected sections, chosen based on the following criteria: sections BB', CC', DD' and EE' have been used to determine the landslide failure surface, while sections FF' and GG', which lie outside the landslide, have been superposed to the others to reconstruct the morphology of the top soil layer prior to the slope instability. Section AA' was also considered in the 3D definition of the model as located close to the borehole used to define the local stratigraphy. The resulting volume of the landslide mass, equal to about $2000 \mathrm{~m}^{3}$ when estimated through the geometrical reconstruction described above (Figure 1b), is in good agreement with the data reported by local authorities.

The points cloud model has also been adopted to build the structural model, for which volumes have been extruded from horizontal sections, at different heights. 


\subsection{Back-analyses of the slope}

Two boreholes have been drilled in the vicinity of the Monastery, both indicating the presence of a top layer of clayey soil, 4 to $5 \mathrm{~m}$ thick, overlaying the calcareous bedrock. A limited number of laboratory tests were available, all referred to the intact state of the soil stratum, while those acting along the failure surface have been deduced through a back-analysis of the slope stability conditions. At this scope, 2D analyses were performed under the hypothesis of plain strain conditions and referring to an equivalent simplified geometry, adopting for the limit equilibrium approach the one proposed by Morgenstern \& Price [14].

The laboratory investigations and the back-analysis lead to the definition of set of parameters reported in Table 1; the 2D back-analysis also shows that the triggering hydraulic conditions correspond to a water table located $4.0 \mathrm{~m}$ below the ground level and about parallel to it.

Table 1: Soil parameters

\begin{tabular}{ccccc}
\hline$\gamma$ & $E^{\prime}$ & $v^{\prime}$ & $c^{\prime}$ & $\phi^{\prime}$ \\
\hline $\mathrm{kN} / \mathrm{m}^{3}$ & $\mathrm{MPa}$ & & $\mathrm{kPa}$ & $\circ$ \\
\hline 19 & 50 & 0.15 & 25 & 24 \\
\hline
\end{tabular}

\subsection{Structural damage and material characterization}

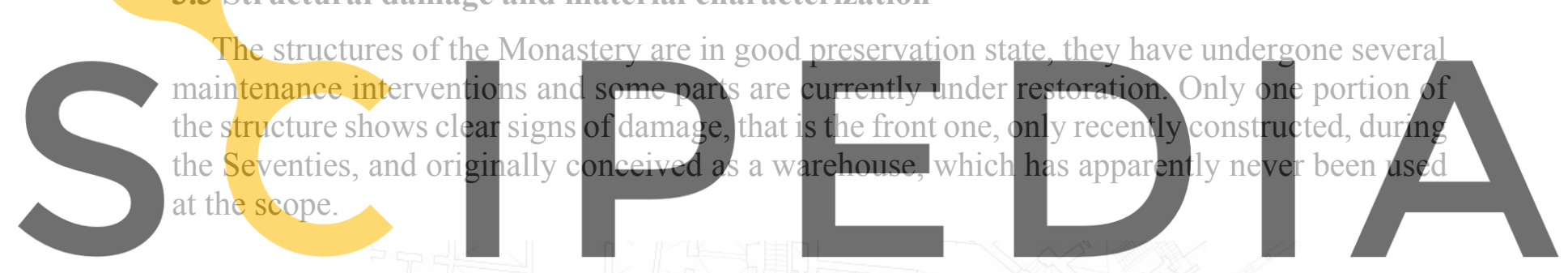

Register for free at https//www.scipedia.com to download the version without the watermark
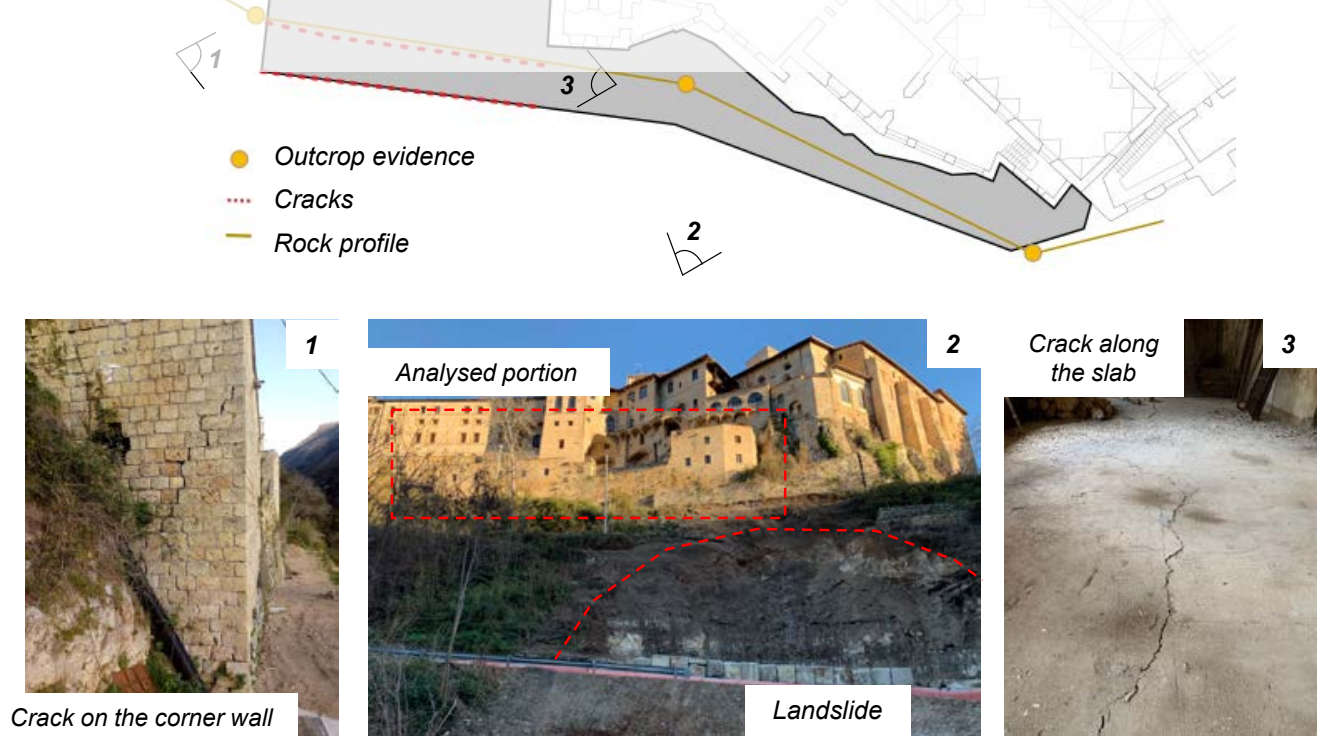

Figure 2: Visual inspection in the warehouse building 
Thanks to a visual inspection of the structure, the main evidences of damage were located, rock outcrop profile directly interacting with the structure was obtained through interpolation of some outcrop points and masonry typology was identified in some parts of the building (Figure 2). The structure has been constructed with poor-quality masonry with irregular stones, covered by an external facing of regularly bonded calcareous stones.

Mechanical properties assigned to the masonry are reported in Table 2 and refer to the Jointed Masonry model described in the previous section. In this case, an isotropic elastic behaviour is assumed, and the strength parameters are assigned according to the identified masonry typology (disordered rough stone masonry) and current code prescriptions [15].

Table 2: Masonry parameters

\begin{tabular}{cccccc}
\hline$c_{0, i}$ & $\sigma_{t 0, i}$ & $\phi_{i}$ & $\beta$ & $G$ & $\gamma$ \\
\hline $\mathrm{kPa}$ & $\mathrm{kPa}$ & $\circ$ & - & $\mathrm{MPa}$ & $\mathrm{kN} / \mathrm{m}^{3}$ \\
\hline 20 & 20 & 31 & 0.3 & 350 & 19 \\
\hline
\end{tabular}

\section{NUMERICAL MODELLING}

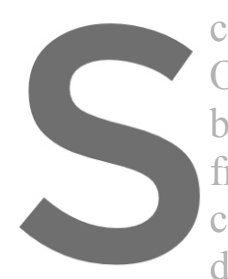

The three-dimensional model adopted to analyse the interaction problem has been constructed in the software PEAXIS 3D and is made out of 63381 solid 10-noded elements. Only the most recent by damage. In fact, the

from the rest of the agg clearly visible. The analyses were performed a detected damage on the structure, then at under

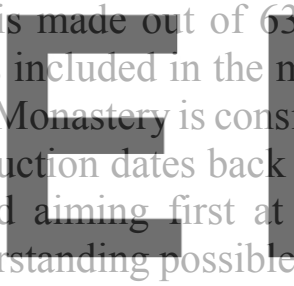
model, as the only
sidered structurally i
to 1970 , and joint-
identifying the cat one affected
independent
-sections are
auses of the
mena during the landslide event, which could have possibly worsened the pre-existing damage pattern.

Register for free at https//www.scipedia.com to download the version without the watermark 4.1 Settlements induced damage and landslide scenario

The first analysed scenario does not consider the landslide occurrence but focuses on the effects of the heterogeneous soil foundation conditions on the structure. In particular, the model accounts for the fact that the building is partly founded on the stiff bedrock and partly on the softer silty deposit; this condition is responsible of both the cracking of the first-floor slab and the damage on the corner external wall, as indicated by the results summarized in Figure 3. This crack pattern is expressed in terms of maximum tensile strain and plastic points distribution on the horizontal slab and on the western wall respectively.

The landslide is then simulated according to the procedure described in Section 2, while monitoring the configuration of the structure at the end of each stage. It is shown that no sensitive change in tensile strain and plastic points distribution can be related to the occurrence of the landslide.

The results are in line with the vertical displacement graph plotted on the monitored line section, which has been chosen as running parallel to the floor on the most damaged wall. Figure 4a) reports the displacement measured on the section highlighted in bold in Figure 4b). The preand post-event scenarios are plotted together with a solid black line, outlining the correspondent 
quantities in the ideal case of rigidly supported foundations. This line shows that, albeit negligible, a vertical displacement could be ascribed to masonry deformability.

These information allowed to conclude that a significant interaction between the structure and the soil only took place during the construction stages, leading to the observed damage pattern, while no further displacements occurred at the control points during and after the landslide.
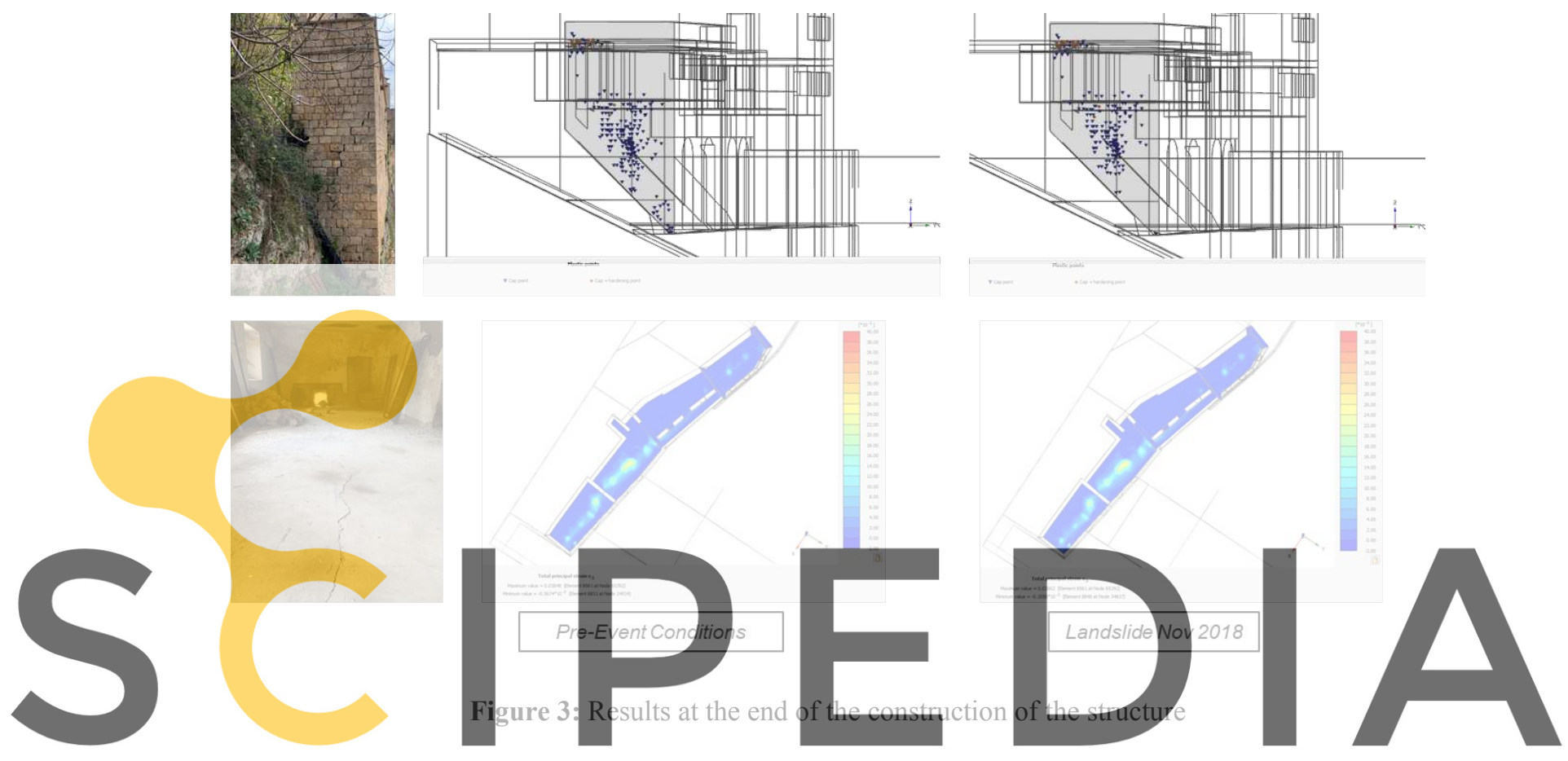

Register for free at https//WWw.s'cipedia.com to downhload the version without the watermark

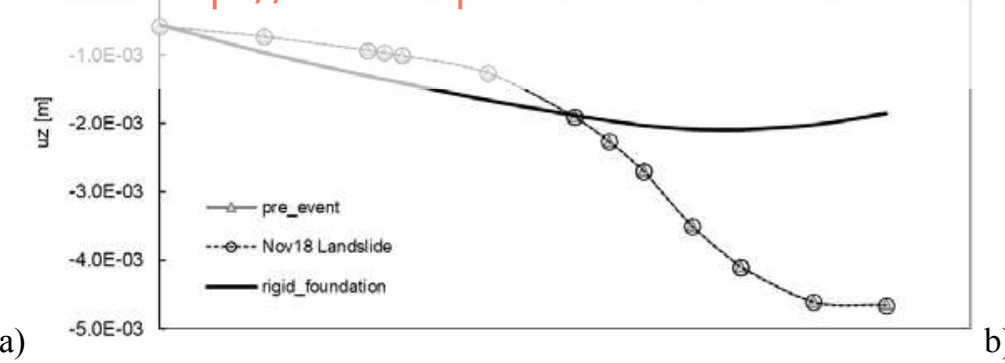

b)

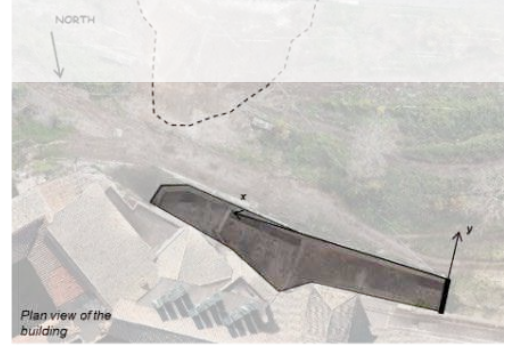

Figure 4: Vertical displacement in the three scenarios

\section{CONCLUSIONS}

In this work a fully coupled soil-structure interaction analysis was performed, in order to determine possible effects of a landslide occurred near a monumental building. During postevent surveys some damage was identified and possible interaction with the slope, that might have worsened the safety conditions of the structure, had to be evaluated and/or excluded.

A semi-automatic procedure, stemming from laser scanner survey, allowed to build a three dimensional model in which the geometrical complexity of the structure and the interacting 
rock and soil strata was preserved and reproduced. A series of preliminary back analyses were performed to get an a-posteriori definition of the mechanical properties of the soil and of the triggering condition of the event. A fully coupled geotechnical and structural finite element analysis was then performed in order to have an insight into the possible evolution of damage to identify its causes. The analysis was carried out considering the different stages that characterise the evolution of the site, from the construction of the structure to the occurrence of the landslide. The results show that the structural damage detected in the survey should be ascribed to foundation differential settlements occurred at the construction stages, due to some remarkable heterogeneity of the local subsoil, thus excluding any landslide-related worsening effect.

Acknowledgements. This research has been funded by the Regione Lazio SiCura 20182020 (Tecnologie sostenibili per la protezione SIsmica del patrimonio Culturale).

\section{REFERENCES}

[1] Puzrin, A. M., Alonso, E. E. and Pinyol, N. M. Geomechanics of failures. Springer Science \& Business Media, (2010).

[2] Canuti P., Margottini C., Fanti R. and Bromhead E.N. Cultural Heritage and Landslides: Research for Risk Prevention and Conservation. In: Sassa K., Canuti P. (eds) Landslides - Disaster Risk Reduction. Springer, Berlin, Heidelberg (2009).

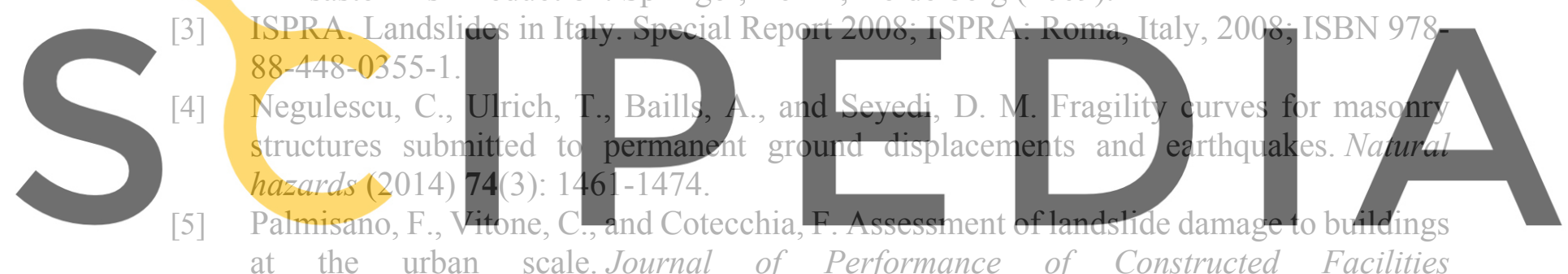

Register for free0abhttps)/.twow\&0.scipedia.com to download the version without the watermark

[6] Parisi, F., Galasso, C., and Sabella, G. Fragility of reinforced concrete framed structures to flow-type landslides. In: 12 th International Conference on Applications of Statistics and Probability in Civil Engineering (ICASP12) (2015).

[7] Ferlisi, S., Nicodemo, G., Peduto, D., Negulescu, C., and Grandjean, G. Deterministic and probabilistic analyses of the 3D response of masonry buildings to imposed settlement troughs. Georisk: Assessment and Management of Risk for Engineered Systems and Geohazards, (2019), 1-20.

[8] Fargnoli, V., Boldini, D., and Amorosi, A. Twin tunnel excavation in coarse grained soils: observations and numerical back-predictions under free field conditions and in presence of a surface structure. Tunnelling and Underground Space Technology (2015) 49: 454469.

[9] Zienkiewicz, O.C. and Taylor, R.L. The finite element method. McGraw Hill, Vol. I., (1989), Vol. II, (1991).

[10] Griffiths, D. V. and Lane, P. A. Slope stability analysis by finite elements. Geotechnique (1999) 49(3), 387-403.

[11] Lasciarrea, W. G., Amorosi, A., Boldini, D., de Felice, G., and Malena, M. Jointed Masonry Model: A constitutive law for 3D soil-structure interaction 
analysis. Engineering Structures (2019), 201: 109803.

[12] Sangirardi, M., Malena, M., and de Felice, G. (2019) Settlement-induced crack pattern prediction through the jointed masonry model. In: AIMETA 2019 XXIV conference. The Italian Association of Theoretical and Applied Mechanics, Rome, Italy (2019).

[13] Castellazzi, G., D’Altri, A. M., de Miranda, S., and Ubertini, F. An innovative numerical modeling strategy for the structural analysis of historical monumental buildings. Engineering Structures (2017) 132: 229-248.

[14] Morgenstern, N.U. and Price, V.E. The analysis of the stability of general slip surfaces. Géotechnique (1965) 15(1): 79-93.

[15] NTC, 2018. Ministero Infrastrutture e Trasporti (MIT). D.M. 17.01.2018. Norme Tecniche per le Costruzioni. Rome, Italy.
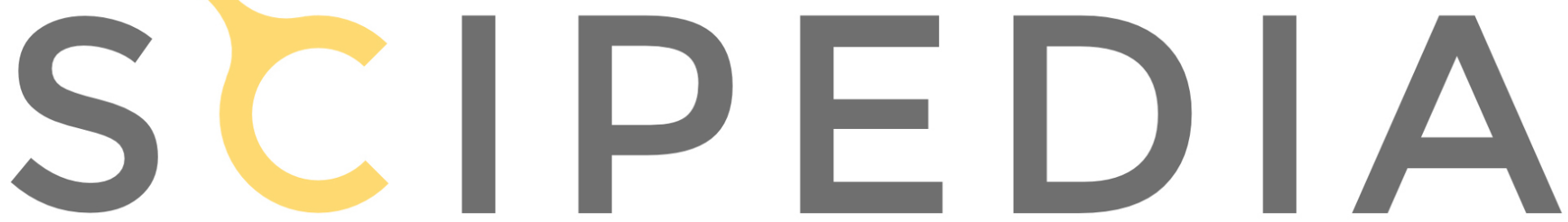

Register for free at https//www.scipedia.com to download the version without the watermark 